ORIGINAL ARTICLE

\title{
mRNA expression of genes involved in lipid efflux and matrix degradation in occlusive and ectatic atherosclerotic disease
}

\author{
S Soumian, R Gibbs, A Davies, C Albrecht
}

J Clin Pathol 2005;58:1255-1260. doi: 10.1136/icp.2005.026161

See end of article for authors' affiliations ......................

Correspondence to: Dr S Soumian, Department of Vascular Surgery, Imperial College, Charing Cross Hospital, Fulham Palace Road, London W68RF, UK; sonis@ doctors.org.uk

Accepted for publication 11 April 2005
Background: Atherosclerotic plaque behaviour is influenced by intraplaque inflammation, matrix turnover, and the lipid core volume. Peroxisome proliferator activated receptor $\gamma$ (PPAR $\gamma$ ) modulates atherosclerosis by its anti-inflammatory and anti-protease activity. PPAR $\gamma$ promotes lipid efflux through the liver $\mathrm{X}$ receptor $\alpha(\mathrm{LXR} \alpha)$ and the ATP binding cassette transporter A1 (ABCA1). Matrix metalloproteinase 9 (MMP-9) and cyclooxygenase 2 (COX-2) are implicated in plaque instability.

Aims: To assess the expression of these genes in occlusive and ectatic atherosclerotic disease to determine the relation between genes involved in lipid efflux and matrix degradation.

Methods: Carotid endarterectomy specimens from 16 patients and aneurysm tissue from 16 patients undergoing abdominal aortic aneurysm repair were used. Inferior mesenteric arteries from colectomy specimens from 12 patients served as controls. Total RNA was extracted from pulverised tissue and reverse transcribed into CDNA. Quantitative real time polymerase chain reaction (PCR) was performed using fluorescently labelled probes for ABCA1, LXR, PPAR , COX-2, and MMP-9.

Results: PPAR $\gamma$ expression was significantly lower in both occlusive and ecstatic atherosclerotic disease $(p<0.001)$, whereas $L X R \alpha$ and $A B C A 1$ expression was significantly increased $(p<0.01)$. MMP-9 expression was significantly increased in diseased tissues $(p<0.0001)$, and values were highest in occlusive disease $(p<0.01)$. The increases in $A B C A 1$ and MMP-9 mRNA were significantly correlated in diseased tissues $(p<0.01, r=0.71$ and $r=0.78)$. COX-2 expression was increased in ectatic but low in occlusive disease $(p<0.01)$.

Conclusion: This observational study suggests a role for therapeutic upregulation of PPAR $\gamma$, which could potentially upregulate lipid efflux through $A B C A 1$ and inhibit matrix degradation through inhibition of MMP-9.
$\mathrm{T}$ he clinical progression of the atherosclerotic plaque is governed by the key processes of inflammation, lipid deposition, and matrix degradation. Increased uptake of modified low density lipoprotein (LDL) by monocytes/ macrophages results in foam cell formation, the hallmark of an atheromatous plaque. ${ }^{1}$ A large lipid core, formed from the extracellular accumulation of these foam cells, ${ }^{2}$ is recognised as a risk factor for plaque rupture. ${ }^{3}$ Increased activity of both proinflammatory cytokines and the matrix degrading matrix metalloproteinases, particularly in the region of the fibrous cap, can render the atherosclerotic plaque potentially unstable. ${ }^{4}$

"A strategy that could combine both promotion of cholesterol efflux, and inhibition of inflammation and matrix degradation, would be of great benefit in treating or modifying plaque behaviour"

Ubiquitously expressed nuclear factor $\mathrm{\kappa B}$ transcription pathways, ${ }^{5}$ involved in the activation of cytokines such as cyclooxygenase 2 (COX-2), ${ }^{67}$ have been implicated in plaque instability. ${ }^{8}$ COX-2, mainly expressed in atherosclerotic lesions, ${ }^{9}$ is involved in the release of matrix metalloproteinase 9 (MMP-9), ${ }^{10}$ a matrix degrading protease, which has been reported to play a major role in atheromatous plaque rupture. ${ }^{11}$ A strategy that could combine both promotion of cholesterol efflux, and inhibition of inflammation and matrix degradation, would be of great benefit in treating or modifying plaque behaviour.

\begin{tabular}{|c|c|c|c|}
\hline Characteristics & $\begin{array}{l}\text { CEA group } \\
(n=16)\end{array}$ & $\begin{array}{l}\text { Aneurysm group } \\
(n=16)\end{array}$ & $\begin{array}{l}\text { Controls } \\
(n=12)\end{array}$ \\
\hline Age (mean) & 72 & 75 & 70 \\
\hline \multicolumn{4}{|l|}{ Sex } \\
\hline Male & 8 & 14 & 6 \\
\hline Female & 8 & 2 & 6 \\
\hline Smoking & 1 & 6 & 2 \\
\hline Diabetes & 4 & 2 & 1 \\
\hline Hypertension & 12 & 13 & 5 \\
\hline \multicolumn{4}{|c|}{ Symptomatic peripheral } \\
\hline vascular disease & 1 & 4 & 0 \\
\hline \multicolumn{4}{|l|}{ Drugs } \\
\hline Aspirin & 12 & 10 & 2 \\
\hline Clopidogrel & 2 & 1 & 0 \\
\hline Warfarin & 2 & 1 & 0 \\
\hline Statins & 9 & 5 & 2 \\
\hline
\end{tabular}

One of the most exciting discoveries in recent years has been the peroxisome proliferator activated receptor $\gamma$ $(\operatorname{PPAR} \gamma)$, a nuclear receptor that is involved in the regulation

Abbreviations: $A B C A 1$, ATP binding cassette transporter $A 1$; COX-2, cyclooxygenase 2; Ct, cycle threshold; LDL, low density lipoprotein; $L X R \alpha$, liver $X$ receptor $\alpha ; M M P-9$, matrix metalloproteinase 9; PCR, polymerase chain reaction; PPAR $\gamma$, peroxisome proliferator activated receptor $\gamma$ 
Table 2 Probes for the genes investigated

\begin{tabular}{ll}
\hline Genes & Probe $\left(\mathbf{5}^{\prime}-\mathbf{3}^{\prime}\right)$ \\
\hline ABCA1 & AACTTIAACAAATCCATTGTGGTCGCCTGT \\
$L X R \alpha$ & CACTTCTAGGAGGCAGCCAC \\
PPAR $\alpha$ & ACTCAAGAGTACCAAAGTCAATCAAAGTGGAG \\
COX-2 & ATGATTGCCCGACTCCCTTGGGTT \\
MMP-9 & CCCAGCGAGAGACTCTACACCCGG \\
\hline
\end{tabular}

of both the inflammatory response and lipid homeostasis in the macrophage. ${ }^{12}$ Nuclear receptors like PPAR $\gamma$ and the liver $\mathrm{X}$ receptor $\alpha(\mathrm{LXR} \alpha)$ are known to modulate atherogenesis at various stages from cell recruitment to lipid accumulation and the local inflammatory response. ${ }^{13-16}$ PPAR $\gamma$ is known to suppress monocyte chemoattractant protein 1 expression, ${ }^{17}$ inhibit adhesion molecules, ${ }^{18} 19$ and facilitate cholesterol efflux. ${ }^{20} 21$ It promotes cholesterol efflux via ATP binding cassette transporter $\mathrm{Al}$ (ABCAl) (through the upregulation of $\mathrm{LXR} \alpha$ ) dependent ${ }^{20}$ and distinctly ABCAl independent pathways. ${ }^{21} \mathrm{ABCAl}$, a membrane protein involved in cholesterol efflux, is highly expressed in macrophages ${ }^{22}$ and plays a major role in high density lipoprotein metabolism. ${ }^{23}$ It is also implicated in promoting macrophage engulfment of apoptotic cells. ${ }^{24}$ Patients with ABCAl deficiency states, such as Tangier disease, ${ }^{25}$ have virtually no high density lipoprotein and are predisposed to premature atherosclerosis. ${ }^{26}$

PPAR $\gamma$ and LXR $\alpha$ are reported to suppress the synthesis of COX-2 and MMP-9 through their inhibitory effect on nuclear factor $\kappa \mathrm{B}$ pathways. ${ }^{13}{ }^{1427}$ It is interesting to note that PPAR agonists can effectively increase ABCAl expression in addition to the suppression of proinflammatory pathways, including COX-2 and MMP-9. ${ }^{16}{ }^{28}$ All of these functions are pivotal in stabilising a potentially unstable atherosclerotic plaque. PPAR $\gamma$ has the potential to exert pleiotropic effects on the plaque by upregulation of lipid efflux and downregulation of genes governing inflammation. We aimed to evaluate the expression of genes involved in this lipid efflux pathway, and to assess its association with COX-2 and MMP-9 in occlusive and ectatic atherosclerotic disease.

\section{METHODS}

\section{Patients and specimens}

Sixteen carotid plaques were collected from patients with internal carotid artery stenoses of $>70 \%$ undergoing carotid endarterectomy. Fourteen patients were diagnosed with symptomatic carotid disease with a history of transient ischaemic attacks, strokes, or amaurosis fugax, whereas two were asymptomatic. Aneurysm wall specimens were collected from 16 patients undergoing elective abdominal aortic aneurysm repair. Twelve macroscopically normal inferior mesenteric arteries dissected from colectomy specimens of subjects undergoing elective surgery served as controls. These patients were phenotypically free of symptomatic atherosclerotic disease by history, examination, and a normal electrocardiography tracing. Our study had ethical approval from the Riverside research committee and informed consent was obtained from the patients. Table 1 lists the demographic details of the patient and control groups.

\section{Gene expression studies}

RNA isolation and cDNA preparation

Plaques, aneurysm specimens, and control arteries were immediately snap frozen in liquid nitrogen and stored at $-80^{\circ} \mathrm{C}$. Total RNA was extracted from approximately $30 \mathrm{mg}$ of pulverised frozen tissue with the RNeasy mini or lipid tissue mini kit (Qiagen, Hilden, Germany), according to the manufacturer's instructions.

For cDNA synthesis, total RNA (100 ng) was transcribed with a first strand cDNA synthesis kit for reverse transcription polymerase chain reaction (PCR) (Roche, Welwyn Garden City, Hertfordshire, UK), according to the supplier's instructions.

\section{Real time quantitative reverse transcription PCR (Taqman ${ }^{\circledR}$ )}

Primers and probes for Taqman ${ }^{\circledR}$ analysis of $A B C A 1$ mRNA were designed to span two adjacent exons with PrimerExpress software (PE Applied Biosystems, Oxford, UK).

Tables 2 and 3 list the primers and probes for all genes investigated.

Single tube Taqman analysis was performed on an ABI Prism 7700 sequence detection system with 300nM of forward and reverse primers in the presence of a $200 \mathrm{nM}$ 5'FAM-3'TAMRA tagged probe for ABCAl, COX-2, MMP-9, and PPAR $\gamma$ and $900 \mathrm{nM}$ of forward and reverse primers in the presence of a 300nM 5'FAM-3'TAMRA tagged probe for $L X R \alpha$. The internal standard was $\beta$ actin mRNA, assayed with commercially supplied reagents (PE Applied Biosystems). Reactions were carried out in duplicate and contained $5 \mu \mathrm{l}$ of undiluted cDNA in a total volume of $25 \mu \mathrm{l}$.

\section{Quantitation}

The amount of mRNA in cells was calculated according to the relative standard curve method described in the PE user bulletin number 2 . Target quantity was calculated from the standard curve and normalised to $\beta$ actin.

\section{Statistical methods}

The SAS 8.1 program package was used for statistical evaluations (SAS Version 8.e. SAS Institute Inc, Cary, USA. SAS 1999). For statistical analysis of mRNA expression, the $\Delta$ $\mathrm{Ct}$ (cycle threshold) values (Ct target gene $-\mathrm{Ct} \beta$ actin) were used. Samples were tested for normality by means of the UNIVARIATE procedure and the Shapiro-Wilk $\mathrm{W}$ test. The null hypothesis was rejected in none of the samples. We used analysis of variance to test differences among the control group, plaques, and arteries; pair wise significant differences were established using Bonferroni corrected $t$ tests. Sex differences between the patient and control groups were assessed using the $\chi^{2}$ test (FREQ procedure). We tested the significance of the Pearsons correlation coefficient to evaluate the relations between normalised $A B C A 1$ and normalised $M M P-9$. A p value $<0.05$ was considered significant.

Table 3 Primers for the genes investigated

\begin{tabular}{|c|c|c|}
\hline Genes & Forward primer $\left(5^{\prime}-3^{\prime}\right)$ & Reverse primer $\left(5^{\prime}-3^{\prime}\right)$ \\
\hline$A B C A 1$ & GGGAGGCTCCCGGAGTT & GTATAAAAGAAGCCTCCGAGCATC \\
\hline$L X R \alpha$ & CAAGTGTTGGACTGCGTCT & CAGGAATGTTTGCCCTTCTC \\
\hline PPAR $\alpha$ & CCAGTGGTTGCAGATTACAAGTCTG & TTGTAGAGCTGAGTCTTCTCAGAATAATAAG \\
\hline COX-2 & GCCCTTCCTCCTGTGCC & AATCAGGAAGCTGCTTITTACCTIT \\
\hline MMP-9 & GACGACCGGTTTGGCTTCT & AGGGTTTCCCATCAGCATTG \\
\hline
\end{tabular}



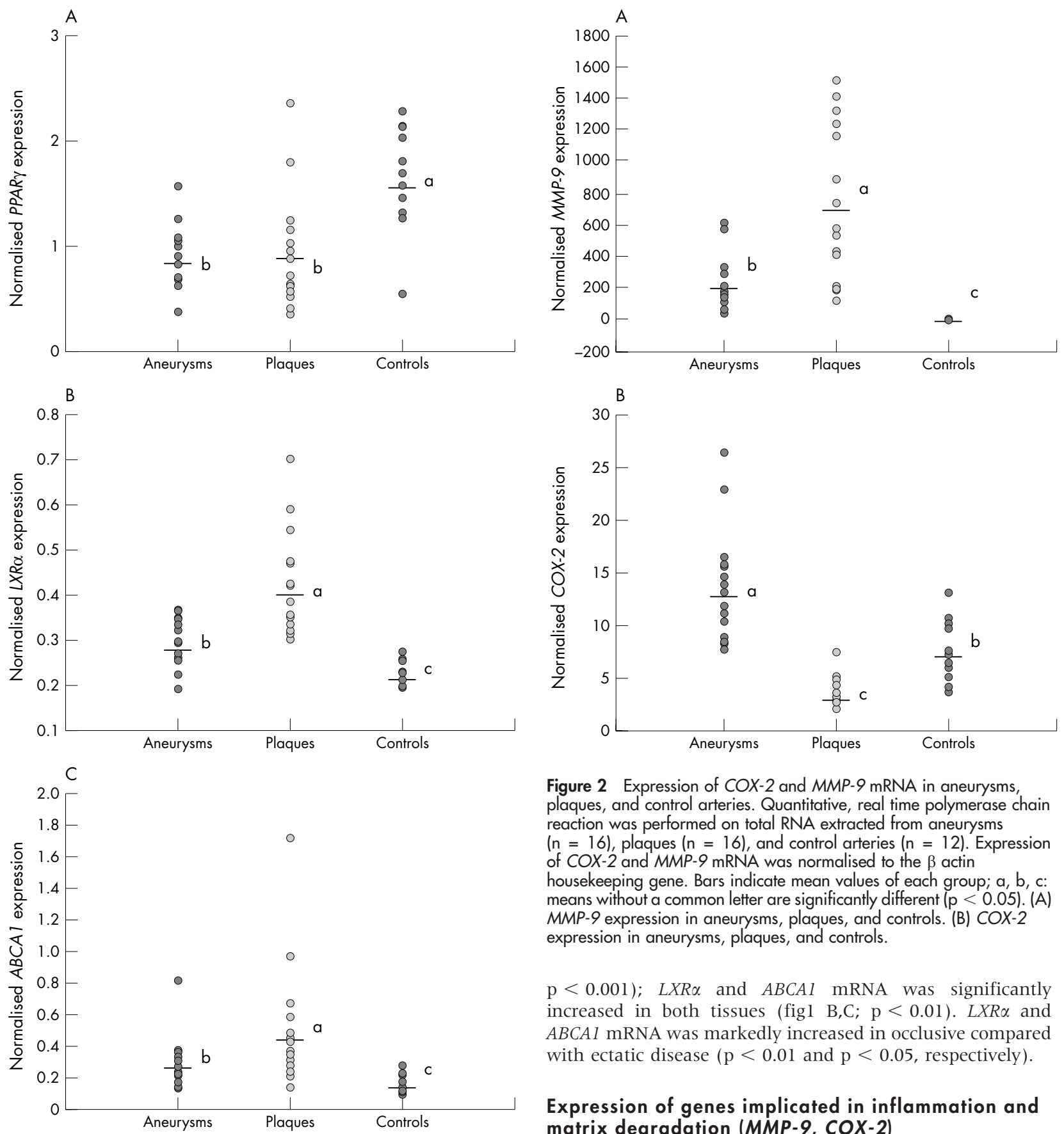

Figure 2 Expression of COX-2 and MMP-9 mRNA in aneurysms, plaques, and control arteries. Quantitative, real time polymerase chain reaction was performed on total RNA extracted from aneurysms $(n=16)$, plaques $(n=16)$, and control arteries $(n=12)$. Expression of COX-2 and MMP-9 mRNA was normalised to the $\beta$ actin housekeeping gene. Bars indicate mean values of each group; $a, b$, c: means without a common letter are significantly different $(p<0.05)$. (A) MMP-9 expression in aneurysms, plaques, and controls. (B) COX-2 expression in aneurysms, plaques, and controls.

$\mathrm{p}<0.001) ; \quad L X R \alpha$ and ABCAl mRNA was significantly increased in both tissues (figl $\mathrm{B}, \mathrm{C} ; \mathrm{p}<0.01$ ). $L X R \alpha$ and $A B C A 1$ mRNA was markedly increased in occlusive compared with ectatic disease $(\mathrm{p}<0.01$ and $\mathrm{p}<0.05$, respectively).

\section{Expression of genes implicated in inflammation and} matrix degradation (MMP-9, COX-2)

$M M P-9$ expression was significantly higher in ectatic and

Figure 1 Expression of PPAR , $L X R \alpha$, and $A B C A 1$ mRNA in aneurysms, plaques, and control arteries. Quantitative, real time polymerase chain reaction was performed on total RNA extracted from aneurysms

$(n=16)$, plaques $(n=16)$, and control arteries $(n=12)$. Expression of PPAR,$L X R \alpha$, and $A B C A 1 \mathrm{mRNA}$ was normalised to the $\beta$ actin housekeeping gene. Bars indicate mean values of each group; $a, b, c$ : means without a common letter are significantly different $(p<0.05)$. (A) $P P A R \gamma$ expression in aneurysms, plaques, and controls. (B) LXR $\alpha$ expression in aneurysms, plaques, and controls. (C) $A B C A 1$ expression in aneurysms, plaques, and controls.

\section{RESULTS}

Expression of genes implicated in lipid efflux (ABCA 1, $P P A R \gamma, L X R \alpha)$

Real time quantitative PCR was used to determine $P P A R \gamma$ mRNA levels in plaques and control arteries. PPAR $\gamma$ expression was significantly lower in occlusive and ectatic atherosclerotic tissues, compared with arterial control tissue (fig 1A; was found in occlusive disease. COX-2 expression was significantly higher in aneurysm tissue (fig $2 \mathrm{~B} ; \mathrm{p}<0.01$ ), whereas it was markedly reduced in atherosclerotic plaques compared with control tissue $(\mathrm{p}<0.01)$.

\section{Association between ABCA1 and MMP-9}

$A B C A 1$ and $M M P-9$ mRNA expression was associated in both occlusive and ectatic atherosclerotic tissues (fig 3A,B; $r=0.71$ and 0.78 for plaques and aneurysms, respectively; $\mathrm{p}<0.01)$.

\section{DISCUSSION}

There is much interest in PPAR $\gamma$ in terms of atherosclerosis because of its potential beneficial effects. It is expressed by all major cells of the vasculature, including endothelial cells, 

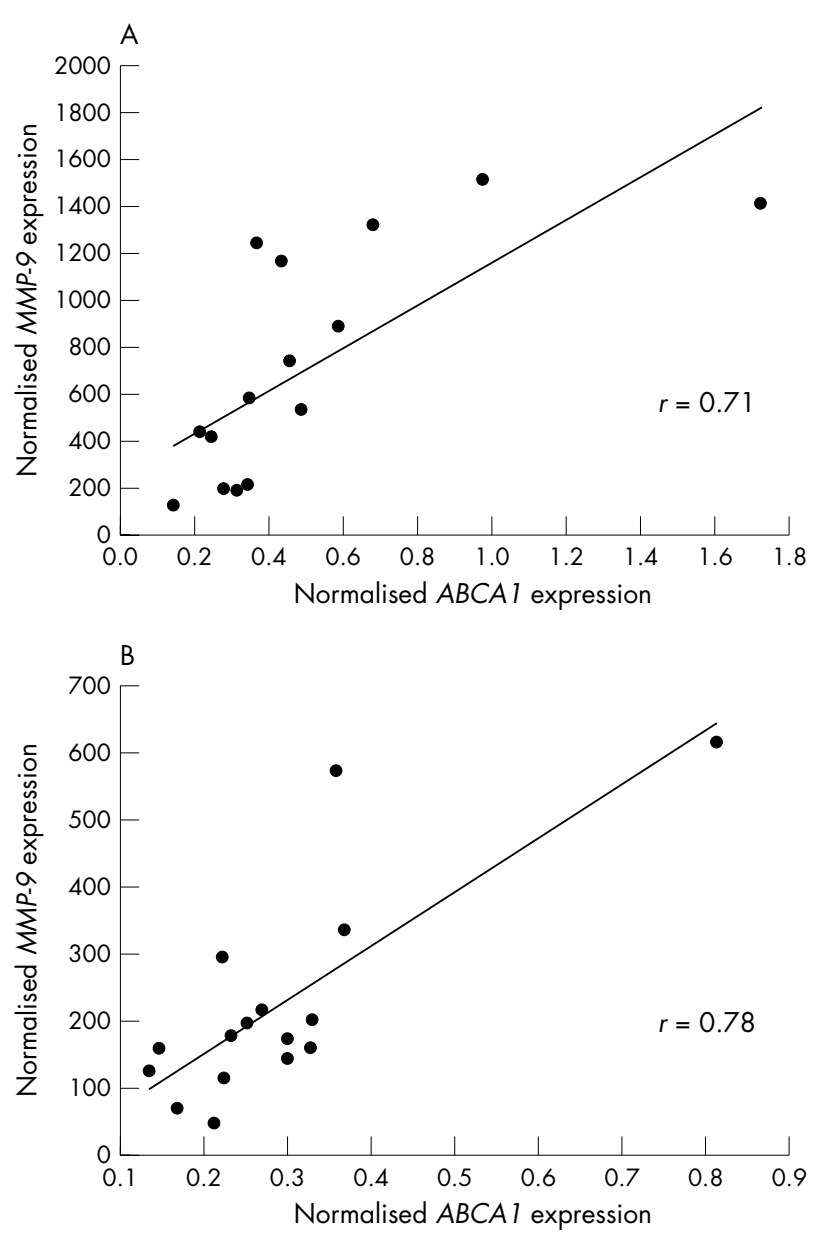

Figure 3 Association between $A B C A 1$ and MMP-9 mRNA values in plaques and aneurysm tissue. $A B C A 1$ and MMP-9 mRNA expression in (A) plaques and (B) aneurysm tissue was measured by real time polymerase chain reaction and normalised to $\beta$ actin.

vascular smooth muscle cells, and monocytes/macrophages. ${ }^{29}$ This receptor can be therapeutically targeted using the thiazolidinediones-a group of drugs such as pioglitazone, rosiglitazone, and troglitazone-agents that have recently been used in the treatment of type 2 diabetes and have proved to be very effective in reducing insulin resistance. ${ }^{30-33}$

It has been shown that PPAR $\gamma$ activation inhibits angiogenesis, which plays an important role in plaque progression and aneurysm formation, ${ }^{34}$ and stimulates the release of nitric oxide from endothelial cells, ${ }^{35}$ which is crucial for the maintenance of normal vascular physiology. Furthermore, drugs like thioglitazones have been found to inhibit intimal hyperplasia ${ }^{36}$ and promote lipid efflux, in addition to reducing inflammation. ${ }^{37}$ The clinical relevance of this has been demonstrated by the fact that less neointima formation was seen after coronary artery stent placement in patients with type 2 diabetes when they were treated with troglitazone. ${ }^{38}$ In vivo studies using LDL receptor knockout mice have shown that PPAR $\gamma$ agonists reduced the development of atherosclerotic lesions. ${ }^{15} 39$

In our present study, we found reduced expression of PPAR $\gamma$ in human atherosclerotic tissues, both occlusive and ectatic, when compared with normal arterial controls, whereas $A B C A 1$ and $L X R \alpha$ expression was significantly upregulated in both types of disease. We have previously reported that ABCAl protein was low in carotid atherosclerotic plaques, despite increased mRNA expression. ${ }^{40}$ We hypothesised that reduced $\mathrm{ABCAl}$ protein leads to an oxysterol rich plaque microenvironment, which in turn stimulates $\mathrm{LXR} \alpha$, with consequent upregulation of the $A B C A l$ gene.

This could explain the high expression of $L X R \alpha$ and $A B C A I$ mRNA in these tissues. The variable degrees of $A B C A l$ and $L X R \propto$ upregulation in both occlusive and aneurismal disease could be attributed to the difference in the availability of ligands activating these genes. The reduced expression of $P P A R \gamma$ in these tissues could potentially result from the increased amount of cytokines in the plaque microenvironment. ${ }^{41}$

Expression of $M M P-9$, which is implicated in the degradation of the plaque fibrous cap, was found to be significantly raised in both types of diseased tissue, but more so in occlusive disease. ${ }^{11} 42$ Although its role in aneurysm formation is not clear, MMP-9 has been extensively studied in the context of plaque pathophysiology. ${ }^{42}{ }^{43}$ Surprisingly COX -2 expression was decreased in atheromatous plaques in our study, whereas expression was significantly higher in aneurysms. Oxidised LDL has been reported to inhibit COX2 in human macrophages in in vitro studies, ${ }^{44}$ suggesting that the impact of macrophage COX-2 may be attenuated in advanced atherosclerotic lesions. ${ }^{45}$

Moreover, oxidised LDL may reach higher concentrations in the plaque than in the aneurysm wall. This also seems to reflect the recent findings that therapeutic COX-2 inhibition may not be beneficial in stabilising the plaque, considering the fact that most of these plaques were symptomatic. ${ }^{46}{ }^{47}$

\section{"Our study underlined the potential link between genes involved in lipid efflux and matrix degradation"}

We found that $A B C A 1$ mRNA expression correlated with MMP-9 expression in both aneurysmal and occlusive specimens. Low concentrations of ABCAl protein in atherosclero-

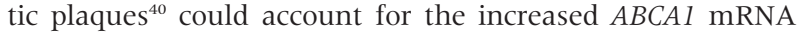
values in these tissues.

Proteases such as calpain have been reported to be involved in $\mathrm{ABCAl}$ protein degradation. ${ }^{48} \mathrm{MMPs}$ are known to degrade non-extracellular matrix proteins in addition to matrix proteins, ${ }^{49}$ and were also found to correlate with calpain in in vitro studies. ${ }^{50}{ }^{51}$ This raises the possibility that common protein degradation pathways involving MMP-9 and calpain may be involved in ABCAl protein degradation, thus promoting matrix degradation and at the same time reducing lipid efflux. In our study, a large proportion of patients in the carotid endarterectomy and aneurysm groups had comorbid conditions and were on aspirin and statins. Conditions such as diabetes mellitus can potentially decrease $A B C A 1$ expression $^{52}{ }^{53}$; however, the effect of hypertension on the expression of these genes has not been reported. Data on the influence of statins on $A B C A 1$ expression are conflicting, ${ }^{54} 55$ although a positive effect on $P P A R \gamma$ expression and suppression of MMP-9 and COX-2 has been reported in various in vitro studies. ${ }^{56} 57$

PPAR $\gamma$ is known to suppress the synthesis of both COX-2 and MMP-9. ${ }^{58-60}$

Considering the low expression of PPAR $\gamma$ in these specimens, it is tempting to speculate that PPAR $\gamma$ upregulation through pharmacological means using thiazolidinediones or synthetic ligands could potentially be beneficial in increasing lipid efflux through LXR $\alpha$ and ABCAl and reducing inflammation through the inhibition of COX-2 and MMP-9, thus stabilising the atherosclerotic plaque.

In conclusion, our observational study revealed low expression of PPAR $\gamma$ in ecstatic and occlusive disease and underlined the potential link between genes involved in lipid efflux and matrix degradation. The interesting finding that reduced PPAR $\gamma$ expression is seen in atherosclerotic tissues 


\section{Take home messages}

- We found that the expression of PPARy (peroxisome proliferator activated receptor $\gamma$; a modulator of atherosclerosis with anti-inflammatory and anti-protease activity) was low in ecstatic and occlusive atherosclerotic disease

- These results suggest that the upregulation of PPAR $\gamma$, by means of thiazolidinediones or synthetic ligands, could be beneficial in the context of treating atherosclerosis

- Upregulation of PPAR $\gamma$ may upregulate lipid efflux through ATP binding cassette transporter $A 1$ and inhibit matrix degradation through inhibition of matrix metalloproteinase 9

raises the possibility that upregulation of this pathway may be beneficial in the context of treating atherosclerosis.

\section{ACKNOWLEDGEMENTS}

The authors would like to thank Dr A Sardini for his contribution towards planning and organisation of the project. This project was supported by the Stroke Association (TSA 12/02) and the Medical Research Council.

\section{Authors' affiliations}

S Soumian, MRC Clinical Sciences Centre, Faculty of Medicine, Imperial College Hammersmith Hospital, Du Cane Road, London W12 ONN, UK R Gibbs, A Davies, Department of Vascular Surgery, Charing Cross Hospital, London W6 8RF, UK

C Albrecht, Physiology Weihenstephan, Technical University Munich, Weihenstephaner Berg 3, Freising, Germany

\section{REFERENCES}

1 Tabas I. Cholesterol and phospholipid metabolism in macrophages [review] Biochim Biophys Acta 2000;1529:164-74.

2 Stary HC, Chandler AB, Glagov S, et al. A definition of initial, fatty streak, and intermediate lesions of atherosclerosis: a report from the committee on vascular lesions of the council on arteriosclerosis, American Heart Association. Circulation 1994;89:2462-78.

3 Mathiesen EB, Bonaa KH, Joakimsen O. Echolucent plaques are associated with high risk of ischemic cerebrovascular events in carotid stenosis: the Tromso study. Circulation 2001;103:2171-5.

4 Plutzky J. Atherosclerotic plaque rupture: emerging insights and opportunities. Am J Cardiol 1999:84:15J-20J.

5 de Martin R, Hoeth M, Hofer-Warbinek R, et al. The transcription factor NFkappa $B$ and the regulation of vascular cell function. Arterioscler Thromb Vasc Biol 2000;20:E83-8.

6 Cipollone F, Prontera C, Pini B, et al. Overexpression of functionally coupled cyclooxygenase- 2 and prostaglandin $E$ synthase in symptomatic atherosclerotic plaques as a basis of prostaglandin $E(2)$-dependent plaque instability. Circulation 2001;104:921-7.

7 Jang BC, Kim DH, Park JW, et al. Induction of cyclooxygenase-2 in macrophages by catalase: role of NF-kappaB and PI3K signaling pathways. Biochem Biophys Res Commun 2004;316:398-406.

8 Martin-Ventura JL, Blanco-Colio LM, Munoz-Garcia B, et al. NF-kappaB activation and Fas ligand overexpression in blood and plaques of patients with carotid atherosclerosis: potential implication in plaque instability. Stroke 2004;35:458-63.

9 MacGeer PL, MacGeer EG, Yasojima K. Expression of COX-1 and COX-2 mRNA in atherosclerotic plaques. Exp Gerontol 2002;37:925-9.

10 Khan KM, Howe LR Falcone DJ. Extracellular matrix-induced cyclooxygenase2 regulates macrophage proteinase expression. J Biol Chem 2004; 279:22039-46.

11 Loftus IM, Naylor AR, Goodall S, et al. Increased matrix metalloproteinase-9 activity in unstable carotid plaques. A potential role in acute plaque disruption. Stroke 2000;31:40-7.

12 Barbier O, Torra IP, Duguay Y, et al. Pleiotropic actions of peroxisome proliferator-activated receptors in lipid metabolism and atherosclerosis. Arterioscler Thromb Vasc Biol 2002;22:717-26.

13 Castrillo A, Joseph SB, Marathe C, et al. Liver X receptor-dependent repression of matrix metalloproteinase-9 expression in macrophages. J Biol Chem 2003;278:10443-9.

14 Joseph SB, Castrillo A, Laffitte BA, et al. Reciprocal regulation of inflammation and lipid metabolism by liver X receptors. Nat Med 2003;9:213-19.
15 Li AC, Brown KK, Silvestre MJ, et al. K. Peroxisome proliferator-activated receptor gamma ligands inhibit development of atherosclerosis in LDL receptor-deficient mice. J Clin Invest 2000;106:523-31

16 Marx N, Sukhova G, Murphy C, et al. Macrophages in human atheroma contain PPARgamma: differentiation-dependent peroxisomal proliferatoractivated receptor gamma (PPARgamma) expression and reduction of MMP-9 activity through PPARgamma activation in mononuclear phagocytes in vitro. Am J Pathol 1998;153:17-23.

17 Murao K, Imachi H, Momoi A, et al. Thiazolidinedione inhibits the production of monocyte chemoattractant protein-1 in cytokine-treated human vascular endothelial cells. FEBS Lett 1999;454:27-30

18 Jackson SM, Parhami F, Xi XP, et al. Peroxisome proliferator-activated receptor activators target human endothelial cells to inhibit leukocyteendothelial cell interaction. Arterioscler Thromb Vasc Biol 1999:19:2094-104

19 Pasceri V, Wu HD, Willerson JT, et al. Modulation of vascular inflammation in vitro and in vivo by peroxisome proliferator-activated receptor-[gamma] activators. Circulation 2000;101:235.

20 Chinetti G, Lestavel S, Bocher V, et al. PPAR-alpha and PPAR-gamma activators induce cholesterol removal from human macrophage foam cells through stimulation of the ABCAl pathway. Nat Med 2001;7:53-8.

21 Li AC, Binder CJ, Gutierrez A, et al. Differential inhibition of macrophage foam-cell formation and atherosclerosis in mice by PPARalpha, beta/delta, and gamma. J Clin Invest 2004;114:1564-76.

22 Lawn RM. Localization of human ATP-binding cassette transporter $1(A B C 1)$ in normal and atherosclerotic tissues. Arterioscler Thromb Vasc Biol 2001;21:378-85.

23 Oram JF, Lawn RM. ABCA1: the gatekeeper for eliminating excess tissue cholesterol. J Lipid Res 2001;42:1173-9.

24 Hamon $\mathrm{Y}$, Broccardo $\mathrm{C}$, Chambenoit $\mathrm{O}$, et al. $\mathrm{ABCl}$ promotes engulfment of apoptotic cells and transbilayer redistribution of phosphatidylserine. Nat Cell Biol 2000:2:399-406.

25 Bodzioch M, Orso E, Klucken J, et al. The gene encoding ATP-binding cassette transporter I is mutated in Tangier disease. Nat Genet 1999;22:347-51

26 Van Dam MJ, De Groot E, Clee SM, et al. Association between increased arterial-wall thickness and impairment in $A B C A 1$-driven cholesterol efflux: an observational study. Lancet 2002;359:37-41.

27 Tedgui A, Mallat Z. Anti-inflammatory mechanisms in the vascular wall. Circ Res 2001;88:877-87.

28 Ruan XZ, Moorhead JF, Fernando R, et al. PPAR agonists protect mesangial cells from interleukin $1[$ beta]-induced intracellular lipid accumulation by activating the $A B C A 1$ cholesterol efflux pathway. I Am Soc Nephrol 2003;14:593-600

29 Ricote $M$, Huang J, Fajas $L$, et al. Expression of the peroxisome proliferatoractivated receptor gamma (PPARgamma) in human atherosclerosis and regulation in macrophages by colony stimulating factors and oxidized low density lipoprotein. Proc Nat Acad Sci USA 1998:95:7614-19.

30 Chen Z, Ishibashi S, Perrey S, et al. Troglitazone inhibits atherosclerosis in apolipoprotein E-knockout mice: pleiotropic effects on CD36 expression and HDL. Arterioscler Thromb Vasc Biol 2001;21:372-7.

31 Fujiwara T, Horikoshi H. Troglitazone and related compounds: therapeutic potential beyond diabetes. Life Sci 2000;67:2405-16.

32 Raji A, Plutzky J. Insulin resistance, diabetes, and atherosclerosis: thiazolidinediones as therapeutic interventions. Curr Cardiol Rep 2002:4:514-21.

33 Ruan H, Pownall HJ, Lodish HF. Troglitazone antagonizes tumor necrosis factor-alpha-induced reprogramming of adipocyte gene expression by inhibiting the transcriptional regulatory functions of NF-kappaB.J Biol Chem 2003;278:28181-92

34 Takeda K, Ichiki T, Tokunou T, et al. Peroxisome proliferator-activated receptor gamma activators downregulate angiotensin II type 1 receptor in vascular smooth muscle cells. Circulation 2000;102:1834-9.

35 Calnek DS, Mazzella L, Roser S, et al. Peroxisome proliferator-activated receptor gamma ligands increase release of nitric oxide from endothelial cells. Arterioscler Thromb Vasc Biol 2003:23:52-7.

36 Bruemmer D, Law RE. Thiazolidinedione regulation of smooth muscle cell proliferation. Am J Med 2003;115(suppl 8A):87S-92S

37 Dandona P, Aljada A. A rational approach to pathogenesis and treatment of type 2 diabetes mellitus, insulin resistance, inflammation, and atherosclerosis. Am J Cardiol 2002:90:27G-33G.

38 Takagi T, Akasaka T, Yamamuro A, et al. Troglitazone reduces neointimal tissue proliferation after coronary stent implantation in patients with noninsulin dependent diabetes mellitus: a serial intravascular ultrasound study. J Am Coll Cardiol 2000;36:1529-35.

39 Collins AR, Meehan WP, Kintscher U, et al. Troglitazone inhibits formation of early atherosclerotic lesions in diabetic and nondiabetic low density lipoprotein receptor-deficient mice. Arterioscler Thromb Vasc Biol 2001;21:365-71.

40 Albrecht C, Soumian S, Amey JS, et al. ABCAl expression in carotid atherosclerotic plaques. Stroke 2004;35:2801-6.

41 Zhang B, Berger J, Hu E, et al. Negative regulation of peroxisome proliferator-activated receptor21 gamma gene expression contributes to the antiadipogenic effects of tumor necrosis factor-alpha. Mol Endocrinol 1996; 10:1457-66.

42 Orbe J, Fernandez L, Rodriguez JA, et al. Different expression of MMPs/TIMP1 in human atherosclerotic lesions. Relation to plaque features and vascular bed. Atherosclerosis 2003;170:269-76.

43 Papalambros E, Sigala F, Georgopoulos S, et al. Immunohistochemical expression of metalloproteinases MMP-2 and MMP-9 in abdominal aortic aneurysms: correlation with symptoms and aortic diameter. Int J Mol Med 2003;12:965-8. 
44 Eligini S, Colli S, Basso F, et al. Oxidized low density lipoprotein suppresses expression of inducible cyclooxygenase in human macrophages. Arterioscler Thromb Vasc Biol 1999;19:1719-25.

45 Linton MF, Fazio S. Cyclooxygenase-2 and inflammation in atherosclerosis. Curr Opin Pharmacol 2004;4:116-23.

46 Bea F, Blessing E, Bennett BJ, et al. Chronic inhibition of cyclooxygenase-2 does not alter plaque composition in a mouse model of advanced unstable atherosclerosis. Cardiovasc Res 2003;60:198-204.

47 Olesen M, Kwong E, Meztli A, et al. No effect of cyclooxygenase inhibition on plaque size in atherosclerosis-prone mice. Scand Cardiovasc J 2002;36:362-7.

48 Wang N, Chen W, Linsel-Nitschke P, et al. A PEST sequence in ABCAI regulates degradation by calpain protease and stabilization of $A B C A 1$ by apoA-I. J Clin Invest 2003;111:99-107.

49 Sternlicht MD, Werb Z. How matrix metalloproteinases regulate cell behavior. Annu Rev Cell Dev Biol 2001;17:463-516.

50 Popp O, Heidinger M, Ruiz-Heinrich L, et al. The calpastatin-derived calpain inhibitor CP1B reduces mRNA expression of matrix metalloproteinase-2 and 9 and invasion by leukemic THP-1 cells. Biol Chem 2003;384:951-8.

51 Postovit LM, Dutt P, Dourdin N, et al. Calpain is required for MMP-2 and u-PA expression in SV40 large T antigen-immortalized cells. Biochem Biophys Res Commun 2002;297:294-301.

52 Uehara Y. Polyunsaturated fatty acids and acetoacetate downregulate the expression of the ATP-binding cassette transporter A1. Diabetes 2002;51:2922-8.
53 Wang $Y$, Kurdi-Haidar B, Oram JF. Liver X receptor-mediated activation of macrophage stearoyl-CoA desaturase generates unsaturated fatty acids that destabilize ATP-binding cassette transporter A1. J Lipid Res 2004;45:972-80.

54 Sone $H$, Shimano $H$, Shu $M$, et al. Statins downregulate ATP-binding-cassette transporter Al gene expression in macrophages. Biochem Biophys Res Commun 2004;316:790-4.

55 Zanotti I, Favari E, Sposito AC, et al. Pitavastatin increases ABCA1-mediated lipid efflux from Fu5AH rat hepatoma cells. Biochem Biophys Res Commun 2004:321:670-4.

56 Cipollone F, Fazia $M$, lezzi A, et al. Suppression of the functionally coupled cyclooxygenase-2/prostaglandin $E$ synthase as a basis of simvastatindependent plaque stabilization in humans. Circulation 2003;107:1479-85.

57 Grip O, Janciauskiene S, Lindgren S. Atorvastatin activates PPAR-gamma and attenuates the inflammatory response in human monocytes. Inflamm Res 2002;51:58-62.

58 Hetzel M, Walcher D, Grub M, et al. Inhibition of MMP-9 expression by PPARgamma activators in human bronchial epithelial cells. Thorax 2003;58:778-83

59 Mendez M, LaPointe MC. PPARgamma inhibition of cyclooxygenase-2, PGE2 synthase, and inducible nitric oxide synthase in cardiac myocytes. Hypertension 2003;42:844-50

60 Worley JR, Baugh MD, Hughes DA, et al. Metalloproteinase expression in PMA-stimulated THP-1 cells. Effects of peroxisome proliferator-activated receptor-gamma (PPAR gamma) agonists and 9-cis-retinoic acid. J Biol Chem 2003;278:51340-6. 